\title{
Psychological Correlates of Achievement in Sports among Nigerian Adolescents
}

\author{
Uzoka, R. N. \\ Department of Agricultural and Home Economics Education, \\ Michael Okpara, University of Agriculture Umudike, Abia State, Nigeria
}

Nnaedozie C. A.

Sports Unit, Michael Okpara University of Agriculture Umudike, Abia State, Nigeria

\section{Doi:10.5901/mjss.2013.v4n12p49}

\section{Abstract}

The study investigated the relationship between personality traits of extroversion-introversion and neuroticism and achievement of Nigerian adolescents in sports. The design of the study was correlation survey design. The sample was 356 students from the 3 education zones in Abia State of Nigeria who have won different prizes in sporting competitions both at local, state and national levels. The study therefore adopted a purposive sampling technique. Two research hypotheses guided the study. The instruments for data collection were Eysenck personality inventory (EPI) and student's achievement record in different sporting competitions. The study employed multiple correlation statistics to establish the nature of relationship that exist between extroversionintroversion, neuroticism and achievement in sports of adolescents. The result shows that personality traits of extroversion-introversion and neuroticism were related to achievement in sporting activities. It was therefore recommended that highly neurotic athletes may need special help, particularly to keep their neuroticism under control and direct them among others.

Keywords: extroversion-introversion, Neuroticism, achievement and competitive Sports.

\section{Introduction}

Three significant cultural needs appear predominant in the social setting. These could be grouped as the individual search for identification, search for emotional stimulation and striving for excellence or achievement status, be it in business, politics, academic and sports (Amuchie, 1984). Sports provide an intriguing clue to the complex societal culture, which parallels the establishment of many behaviour patterns within the society. Consequently, sports appears to be the mirror of the society by reflecting through its structure, how people live, work and play and could even serve as a barometer for determining a nation's level of civilization United Nations (2003). Contemporary sports competition has become a crusade against apartheid, a test of endurance and explosive power between the white and black race and a political tool to determine the strength of the various states and achieving national unity (Osugo, 1974 and Osugo 1976).

Uzoalor, (2007) asserts that the basic needs of life can be acquired through sports achievement and competition. Ojeme (2007) stressed that sports could be used to enhance nature reformation of democratic processes in countries. Adelusi et al (2012) noted that very rich and developed countries dominate sports because sports require and contribute to economic stability in any nation. Alderman (1974) outlined three factors that determine whether an individual will achieve in sports or not. These include his genetic endowment that is his biological make up as a member of the species (Homo - sapiens), his past 
environmental history as an individual and specific situation aspects of his current environment. Gabriel (2011) explained further on the above factors that others excel in competitive sports because they have been exposed to reward structures or social environment. Individual differences which involve extroversion and introversion are personality traits which determine how far an individual will achieve in sports. The term extroversion and introversion according to Jung's typology are the personality subscripts of individual's descriptions of surface behaviour (Chauhan 1981).

Consequently, the lives of many people have been ruined through preparation for and participation in sports. There have been a lot of athletes struggling day and night to become stars, training diligently, but never made it. Some have tried numerous drugs, induced hormones, diets and many other physical substances to enhance athletic performance. The urge and ability to achieve in sports or physical activities are due to many recognized and intangible processes that encompass the previous and motivational status.

Characteristically, the typical extrovert is an individual who enjoys change and variety and is oriented towards the external world of people and experience. On the other hand, the introvert is more concerned with stability and with inner world of thoughts and feelings. Individuals find their place at some point on this dimension between extreme extroversion and introversion (Entwistle, 1972). Extroverts are cheerful, outgoing, social, talkative and does not like to be alive while introverts are cold, retiring and aloof. However, Eysenck and Alderman (1974) made some interesting predictions that:

a. Introverts tend to perform better in vigilance task, have greater tolerance for sensory deprivations, and have less tolerance for physical pain.

b. Extroverts have superior memory or recall over short periods of time, have higher threshold of arousal, and show greater physical persistence.

Neuroticism is the act of worrying a lot, moodiness and often depressed state. A neurotic subject or athlete in highly emotional and takes a long time to calm down tends to sleep poorly and suffers from psychosomatic disorders. This variable is related to liability of autonomic nervous system (Chauhan, 1981). Eysenck expanding on the dimensions of neuroticism says it measures a person's level of stability instability. While stable people are calm, even-tempered, and reliable, unstable people are moody, anxious, and unreliable. He maintains that it has physiological basis. The level of human performance in sports is a product of neuro-hormonal stimulation's, causing excitation of the central nervous system. The concept of stimulation results in the excitation of the autonomic nervous system which causes arousal in athletes. Arousal states are placed on a continuum from high to low levels. A low level of excitation or arousal is characterized by lack of alertness and excitement which results in poor performances. On the other hand over excitation or arousal results in high anxiety or neuroticism which may result to the short term effect of reduction in efficiency and effective general task production, misguiding the athlete's attentions lowers optimal arousal of the athletes, thereby reducing their mental and physical readiness to perform in sports. It is only at moderate level of excitation that athletes perform their best.

\section{Statement of the Problem}

The concept of participation in sports for love of it has lost grounds in the modern days. Sports has become entertainment industry as well as big business. Therefore, winning confers on the athletes and their nations immense benefits, increase in status, honours and glory as well as material rewards so that a star athlete can be lifted from parentage to the status of an ambassador at international level. In consequence most youths the world over want to achieve this glory through sports. Hence competition has become more complex, fiercer and more aggressive.

Many students willing to attain this level of achievement in sports but never realized it. Perhaps only an insignificant number has been able to achieve this glory in the past. Therefore this study is specifically designed to determine the relationship between personality traits of extroversion, introversion, neuroticism and achievement of adolescents in sports competition. 


\section{Purpose of Study}

The purpose of this study is to find out the relationship between some personality traits and achievement in sports. It will among other things determine the following:

i. If there is a relationship between extroversion and achievement in sports among Nigerian adolescents.

ii. If there is a relationship between introversion and achievement in sports among Nigerian adolescents.

iii. If there is a relationship between neuroticism and achievement in sports of Nigerian adolescents.

\section{Hypotheses}

1. There is no significant relationship between the personality traits of extroversion-introversion and achievement of Nigerian adolescents in sports.

2. There is no significant relationships between personality traits of neuroticism and achievement in sports of Nigerian adolescents.

\section{Methodology}

The design is a correlation study. Area of study is made up of the three education zones in Abia State of Nigeria. These include Umuahia, Ohafia and Aba Zones. There are 17 Local Government Areas in these 3 zones. There are 440 secondary schools. The students population is 74,088 , (Males, 31,629 and 42,459 females) SSMB 2013. A purposive sampling was adopted to collect records of three hundred and fifty - six (356) students from the education zones. The students who were selected were those that have represented their schools either in local, state or national sports competition. From Aba Education zone 135 students was picked, from Umuahia education 122 and from Ohafia education zone 99 students giving a total of 356 students

The following instruments were used to generate data for the study.(i).Eysenck Personality Inventory (EPI) (ii) Achievement records of students performance in athletic competition from their various schools.Eysenck Personality Inventory (EPI): the local version of the Eysenck Personality Inventory (EPI) scale was adapted by Amajirionye (1982). The inventory has original average text-retest reliability of between 0.70 to 0.80 , but locally, the neuroticism stability ( $N-S$ ) and extroversion-introversion (E-S) respectively produced split half reliability indices of 0.73 (Uncorrected), 0.84 (Corrected) and 0.69 (uncorrected), 0.86 (corrected). The inventory was utilized to elicit some personality traits such as extroversion introversion and neuroticism. The inventory has 57 items, 25 of these items measured traits of neuroticism and seven filler items which were not part of the dimensions were omitted. Each of the other items got a score of one point. Therefore, the maximum score for the dimensions extroversion-introversion and neuroticism were 25. Low score on neuroticism $(N)$ were interpreted as either low $(N)$ or stability which means lack of drive. A low score on extroversion $(F)$ were interpreted as low $(E)$ or introversion. Dependent on the average scores, subjects could be high, low or mid way in the dimension. Further validation of the instrument was done by the researches to determine the internal consistency of the respondents to the items of the questionnaire. The scores from the respondents were analyzed and coefficient calculated using spearman's method. The coefficient of reliability was found to be 0.76 , this shows a high reliability.

Student's achievement records in different sports activities from 2008-2011 was another instrument used for the study. The record/inventory was collected from the principals of the schools used with the help of the sports masters and mistresses of the various schools. The inventory or records has the following graduations, $1^{\text {st }}$ position as Gold medal, $2^{\text {nd }}$ position as silver and $3^{\text {rd }}$ position as bronze medal, respectively. For purpose of scoring was weighted and quantified as Gold or $1^{\text {st }}$ position 3 points, silver or $2^{\text {nd }}$ position 2 
points and bronze or $3^{\text {rd }}$ position 1 point. Based on the weighting the total scores for each student were obtained by summation of the scores for number of medals won. The data generated was analyzed using correlation analysis and z-test.

\section{Results}

Hypothesis 1 there is no significant relationship between the personality trait of extroversion - introversion and achievement in sporting activities among adolescents.

\begin{tabular}{|c|c|c|c|c|c|c|}
\hline Variables & $\mathrm{N}$ & $\mathrm{R}$ & $\begin{array}{c}\text { Z- } \\
\text { Calculat }\end{array}$ & $\begin{array}{l}\text { Z- } \\
\text { Critic }\end{array}$ & Df & $\mathrm{P}$ \\
\hline Extroversion & & & & & & \\
\hline Introversion and & & & & & & \\
\hline Achievement of & 356 & 0.39 & -26.979 & -1.95 & 355 & $5 \%$ \\
\hline
\end{tabular}

The above table indicates that the z-calculated value of -26.979 is less than the critical z-value of -1.95 at df 355 at $5 \%$ level of significance. The null hypothesis of no significant relationship between personality traits of extroversion - introversion and achievement of adolescents in sports is rejected. The implication is that there is a significant relationship between extroversion - introversion and achievement of adolescents in sports.

Hypothesis 2: There is no significant relationship between personality trait of neuroticism and achievement of adolescents in sports activities.

Table 2 z-test analysis of the relationship between personality trait of neuroticism and achievement of adolescent sporting activities

\begin{tabular}{|c|c|c|c|c|c|c|}
\hline Variables & $\mathrm{N}$ & $\mathrm{R}$ & $\begin{array}{c}\text { Z- } \\
\text { Calcula }\end{array}$ & z- & $\begin{array}{l}\text { Df } \\
\text { al }\end{array}$ & $\mathrm{P}$ \\
\hline \multicolumn{7}{|l|}{ Personality } \\
\hline traits of neuroticism & & & & & & \\
\hline and achievement & 356 & 0.38 & -21.15 & -1.95 & 355 & $5 \%$ \\
\hline
\end{tabular}

Table 2 revealed that the calculated z-value using total achievement (-21.15) is less than the critical z-value $(-1.95)$ at Df 355 and $5 \%$ level of significance. The null hypothesis of no significance relationship between the personality trait of neuroticism and achievement of adolescents in sports is rejected. There is a significant relationship between the personality trait of neuroticism and achievement in sports.

\section{Discussion}

Hypothesis1 states that there is no significant relationship between personality trait of extroversionintroversion and achievement in sports. The result of the hypothesis as revealed in table 1 indicated a calculated z-value of -26.97 which is lesser than the critical z-value -1.95 at Df 355 and $5 \%$ level of confidence using total achievement is sports of the adolescents. The null hypothesis was rejected. The result of the study obviously shows that achievement of athletes in sports could be accounted for by the personality trait of extroversion - introversion dimension. No doubt, the study of personality dimensions of extroversion introversion has been of great concern to sports psychologists, coaches, trainers and others working in this 
area. Gabriel (2011) attested to great relationship of extroversion and introversion in competitive sports, especially the extroverts, citing Alderman (1974) he said that extroverts have superior memory and can recall easily, have higher threshold of arousal, and show greater physical persistence. More scientific research evidence lend support that the level of human performance in sports is a product of neuro-hormonal stimulation causing excitations of the central nervous system. To this (Chado 1986) noted that the interaction has both physiological and psychological implications, influencing level of performance. It was on the basis of this that Korman (1974)and Kane (1972) indicated that individuals physical (athletic) abilities are related to the personality dimensions of extroversion - introversion.

The result of hypothesis 2 as indicated in table 2 reveled a calculated z-value -21.15 which is lesser than the critical z-value of -1.95 at Df 355 and $5 \%$ level of significance using total achievement, the null hypothesis of no significance relationship between personality trait of neuroticism and achievement of adolescents in sporting activities was rejected. The result was not surprising as it was consistent with the findings of similar studies of Kane (1972) and Smith (1988) who found that neuroticism or high emotionality is virtually inherent in competitive sports. In addition to the above Carver and Scheier (1981) noted that a neurotic athlete may not achieve maximally in sports with an athlete of normal personality but adduced that a neurotic athlete should not engage in self-focusing in which unpleasant feelings are continuously rehearsed. Such thought creates and maintains self-doubt which in-turn, results in un-favourable expectancies about future out-comes. Consequently, the state of neuroticism will be heightened, confidence decreases, and the athlete engages in thought about self-doubt. The athlete is closer to a state of withdrawal than approach. They concluded that when fear is high, especially after a negative feedback from a coach, self focus increases awareness of the fear, resulting in interrupted behaviour and withdraw, thus reducing performance and achievement in sports.

\section{Recommendations}

Following the findings these recommendations were made:

1. Personality test scores reflecting high degrees of abstract thinking ability have important implication to the trainer. As the athletes generally possessing reasonably high intelligence are likely to be extroverted and possess stable traits evidencing emotional control and tough mindedness but exceptions to this observations are numerous, so the contemplative athletes must be dealt with differently than the athletes who react without reflections.

2. It is generally conceived that too much anxiety and tension, too much emotional stimulation tends to interfere with the early stages of motor-performance. Most athletes cannot perform when the pressures are too high. The highly neurotic athletes may need special help, particularly to keep neuroticism under control and direct them properly in sports.

3. It is not uncommon for an athlete to allow himself to be distracted since they are extremely complex and their psychological attributes are not permanent. The result of this is usually a very inconsistent and un-satisfying performance and poor achievement. Therefore, every coach, should bear in mind that each athlete requires an individualized training and handling routine to maximize his potentials.

4. Athletes should be encouraged to adopt one of the anxiety management techniques by the psychologists like: mental practice of the skills techniques/patterns of place as a perception of self as a spectator and as a perception of self as an active participant. -Mental rehearsal of the skills. The skills is mentally rehearsed over and over before the actual physical performance.

- Imaging practice: This involves going through the process of imagining the skills in its perfect from before executing the skills.

- Visualization which is the act of conceptualizing the perfect skills as a whole.

- Concentrating and blocking out of anxiety provoking thoughts.

- Engaging in positive self statements. 
- Bio feed back techniques: it is claimed that optimum self regulation is the key to successful sports performance. As the athlete is not struggling with his movement, no muscular tension, perfection is experienced through graceful movement with minimum effort.

The underline process is to move the athlete from an external locus of control to an internal locus of control.

\section{Conclusion}

The most essential aspect of personality trait which are of interest to psychologists, coaches and others connected with the training of athletes is the distinction between extroverts and introverts which characterized a good performer. Given this premise, it could therefore be concluded that extroversion-introversion has a very great affinity to achievement is sporting activities.

\section{References}

Adelusi, J. O, Akinmusere A. K. and Ajewole, P. O. (2012). The reflections of physical education and sports on Nigerian $21^{\text {st }}$ Century. Journal of Qualitative Education Vol. 8 (2), 37-45.

Alderman, R. B (1974). Psychological behaviour in sports. Philadphia W. B. Sauoters Company.

Amajirionwu, S. A. (1982). The predicators of intelligence and academic attainment. Journal of education in developing area (1), 54-58.

Amuchie, F. A. (1984). Violence in sports: The concept, causes and possible solutions. A paper presented at the $14^{\text {th }}$ annual conference of Nigerian Association for Physical, health education and recreation, Sokoto September 9-13.

Chado, M. A (1986). Effects of erogenic drugs on sports performance. Journal of Physical, health education and recreation (3)

Chauhan, S. S. (1981). Advanced Educational Psychology. New Delhi: Vikas Pub. Coy.

Carver, C. S. and scheier, M. F (1981). Attention and self-regulation. A control theory approach to human behaviour. New York: Spinger - Vriage.

Claridge, G. (1967) Personality and arousal Penguim: Bailimore.

Gabriel, C. I. (2011). Competition and Competiveness: A problem for a viable nation. African Journal of Sustainable professional development. Vol. 1 (1), 48-58.

Kane, J. E. (1972). Personality, body concept, and performance in J. E Kane (ed) Psychological Aspects of Physical education and sports. Rentledge and Keyan Paul.

Korman, A. K. (1974). The Psychology of motivation. Englewood New Jersey Englewood Cliffs prentice-Hall.

Ojeme, E. O. (2007). Enhancing national reforms through sports. Journal of sports management and educational research. 3, 1-9.

Osugo, P. (1974). Crusade against apartheid. African sports. Africa 34.

Osugo, P. (1976). The black triumph at montreal Olympics. Africa sport. Africa 16.

Smith, R. E. (1986). Toward a cognitive affective model of athlete burnout. Journal of sports Psychology. 8, 36-50.

United Nations (2003) Sports for development and peace. towards achieving the millennium development goals. Reports from the United Nations Inter Agency Task force. 112-115.

Uzoalor, B. E. (2007). Achieving needs refers through sports. Journal of sports management and education management and education research 3, 10-13. 